\title{
Evaluation of the permeability and in vitro cytotoxicity of functionalized titanate nanotubes on Caco-2 cell line
}

\author{
YASMIN RANJOUS ${ }^{1}$, DÓRA KÓSA ${ }^{2}$, ZOLTÁN UJHELYI ${ }^{2}$, GÉZA REGDON JR. ${ }^{1}$, KRISZTINA \\ ANITA NAGY ${ }^{3}$, IMRE SZENTI ${ }^{3}$, ZOLTÁN KÓNYA ${ }^{3,4}$, ILDIKÓ BÁCSKAY², TAMÁS SOVÁNY ${ }^{1 *}$ \\ ${ }^{1}$ University of Szeged, Institute of Pharmaceutical Technology and Regulatory Affairs, \\ 6720, Szeged, Eötvös u 6., Hungary \\ ${ }^{2}$ University of Debrecen, Department of Pharmaceutical Technology, 4010, Debrecen, Nagyerdei krt. 98, Hungary \\ ${ }^{3}$ University of Szeged, Department of Applied and Environmental Chemistry, 6720, Szeged, Rerrich ter 1, Hungary \\ ${ }^{4}$ MTA-SZTE Reaction Kinetics and Surface Chemistry, Research Group, 6720, Szeged, Rerrich ter 1, Hungary
}

Corresponding author: Tamás Sovány, PhD

Email:sovany.tamas@szte.hu

Received: 19 April 2021 / Accepted: 18 May 2021

Titanate nanotubes (TNTs) are promising vectors for drug delivery due to their unique physicochemical properties such as biocompatibility, mechanical strength, and chemical resistivity. However, considering their strong hydrophilicity, pristine TNTs exert very limited permeability through the intestinal cell layer. The aim of this study was to turn the surface characteristics and thus enhance the permeability of TNTs by functionalization. TNTs were functionalized with trichloro(octyl)silane (TCOS) and magnesium stearate $(\mathrm{MgSt})$. Carbon content and surface free energy of the functionalized TNTs were detected to evaluate the effectiveness of functionalization, by using CHNS analytical and optical contact angle (OCA) measurements, respectively. Caco-2 cell line was applied to test the permeability and the cytotoxicity of the samples. Cytotoxicity was evaluated by using MTT assay. The results revealed that the surface characteristics of TNTs may be adjusted in a wider range with TCOS-TNT than with St, but the samples show higher toxicity. Silane functionalized TNTs may be safe up to $1 \mathrm{mg} / \mathrm{ml}$, while St functionalized TNTs up to $2 \mathrm{mg} / \mathrm{ml}$ concentration. The preparation method of MgSt-TNT was also superior from the aspect of environmental safety. The permeability was suitable for samples with moderate hydrophobicity (aqueous contact angle 60-90\%).

Keywords: cytotoxicity; permeability; functionalization; titanate nanotubes; magnesium stearate; silane derivatives

\section{Introduction}

Titanium dioxide nanoparticles $\left(\mathrm{TiO}_{2} \mathrm{NPs}\right)$ are one of the most commonly applied nanoparticles in various fields, such as building engineering, agriculture, food and cosmetic industry, environmental protection or medicine (1). $\mathrm{TiO}_{2}$ NPs exist in three different structures: as anatase, rutile, and brookite (2) (Figure 1.), which differ in their crystal structure where the $\mathrm{Ti}-\mathrm{O}$ bond length ranges are 1.931- 2.004 $\AA$ for rutile, 1.914- $2.005 \AA$ for anatase and 1.850- $2.099 \AA$ for brookite (3).

Despite that anatase is the most toxic form comparing to rutile and brookite (4), it has more industrial applications due to its photocatalytic activity (2). Moreover, the global market presented 117 various products in food and beverage field based on nanotechnology (5). It is allowed in USA to use $\mathrm{TiO}_{2}$ NPs in foodstuff when its percentage does not exceed $1 \%$ of the total product weight (6). However, Europe is following the "quantum satis" concept (7). Furthermore, a child can take 2-4 times more $\mathrm{TiO}_{2} \mathrm{NPs} / 1 \mathrm{~kg}$ of body weight (bw) per a day in comparison to an adult person, which was determined in Great Britain as $2-3 \mathrm{mg} \mathrm{TiO} / \mathrm{kg}$ bw/day for children less than 10 years old, whereas adults can take about $1 \mathrm{mg} \mathrm{TiO} / 2 / \mathrm{kg}$ bw/day(4). Nevertheless, the vast $\mathrm{TiO}_{2}$ NPs applications in food industry resulted in diverse debates on their safety, regarding to toxicity considerations. $\mathrm{TiO}_{2}$ NPs pigment is categorized as a prospective carcinogenic factor from group $2 \mathrm{~B}$ by the International Agency for Research on Cancer (IARC)(8). In contrast, there is no matter of concern on the safety of E171 (titanium dioxide) in 2016 according to the European Food Safety Authority (EFSA)(7). Nevertheless, there are no adequate research data on the acceptable daily intake of $\mathrm{TiO}_{2} \mathrm{NPs}$ and the safety margin was determined as $2.25 \mathrm{mg} \mathrm{TiO}_{2} \mathrm{NPs} / \mathrm{kg}$ bw/day built on tests involving animals (7).

$\mathrm{TiO}_{2}$ NPs toxicity on human body has been connected mostly to apoptosis (9) and some studies displayed that $\mathrm{TiO}_{2} \mathrm{NPs}$ may cause DNA damage (10) and disturb glucose and lipid homeostasis in mice and rats. In addition, $\mathrm{TiO}_{2} \mathrm{NPs}$ may accumulate in the lungs, alimentary tract, liver, kidneys, 


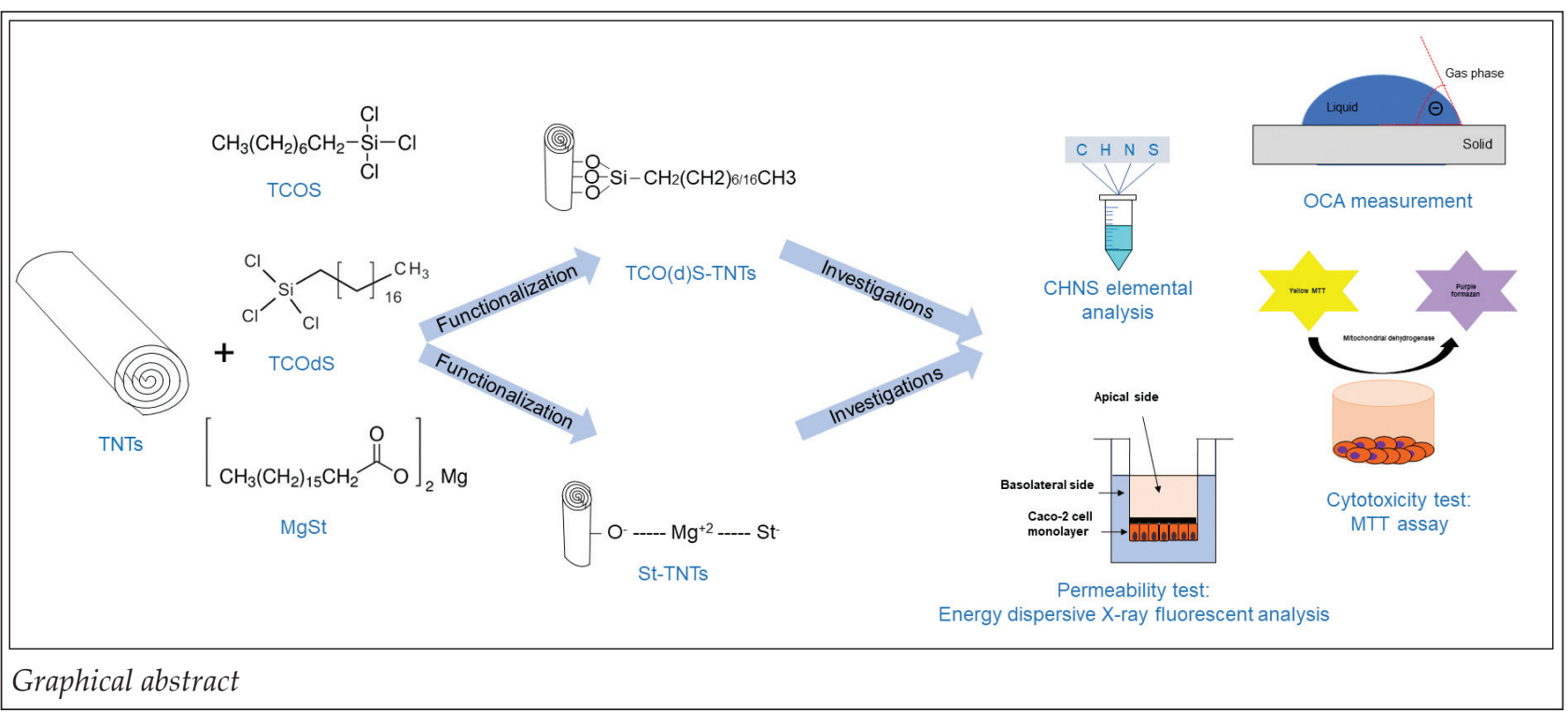

spleen, heart, and cardiac muscle after inhalation or oral exposure (11). Interestingly, the nanoparticle size influences their toxicity and accumulation in different organs in which the larger particles with $80 \mathrm{~nm}$ size are largely assembled in the liver whereas the smaller particles with $25 \mathrm{~nm}$ diameter can accumulate in the spleen and slightly in the lungs and kidneys after a one-time oral administration to mice (12).

$\mathrm{TiO}_{2}$ NPs modification with polyethylene glycol (PEG) decreases the cytotoxicity and the induction of stress-related genes (13). Furthermore, the presence of PEG combining catalytic chain transfer and thiolene polymer layers around $\mathrm{TiO}_{2} \mathrm{NPs}$ leads to not only the reduction of protein adsorption onto their surface, but also the reduction of the size of aggregated particles and the alteration of particle surface chemistry that results in an increased cellular uptake and diminishment of cytotoxicity for both human lung epithelial cell lines A549 and NCI-H1299 (14).

The extent of $\mathrm{TiO}_{2}$ NPs absorption from the gastro-intestinal tract (GIT) into systemic circulation depends on many factors such as species, type of nanoparticles, size, dispersability or particle charging (15). Recent studies indicated that $\mathrm{TiO}_{2}$ NPs were barely transferred from the GIT into the blood circulation in humans and rats. Furthermore, there was no impact of the particle size on their absorption when administrating a single dose of $\mathrm{TiO}_{2} \mathrm{NPs}(5 \mathrm{mg} / \mathrm{kg}$ bw/day) with different particle sizes $(15 \mathrm{~nm} / 100 \mathrm{~nm} /<5000 \mathrm{~nm})$, which may related to their hydrophilicity (16).

$\mathrm{TiO}_{2}$ nanostructures have been reported to cause neurological risk after passing the blood- brain barrier $(17,18)$. Another studies reported the accumulation of $\mathrm{TiO}_{2}$ nanostructures without metabolism in some organs such as the liver and spleen, and with a less degree in the brain, kidneys, lungs, GIT and heart $(19,20)$. Many factors play a role in the tissue distribution of $\mathrm{TiO}_{2}$ nanostructures such as their morphology (21), size and surface charge $(22,23)$.

Different tissue distribution and toxicity profiles were demonstrated after a single and successive intravenous administration of $\mathrm{TiO}_{2}$ nanotubes, rods, and ribbons in rats, in which nanotubes displayed the most toxic effect and the largest accumulation, following that nanorods and ribbons (21).

Ren et al, investigated the toxicity, uptake pathways and excretion of TNTs in three strains of free-living ciliates of the genus Tetrahymena which are a wild type strain (SB210) and two mutant strains (SB255, NP1) (24). The results revealed that TNTs caused cytotoxicity in high concentrations. Using $10 \mathrm{mg} / \mathrm{l}$ of TNTs for $120 \mathrm{~min}$ resulted in their accumulation in NP1 and SB255 in a higher or comparable percentage comparing to SB210, whereas using $10 \mathrm{mg} / \mathrm{l}$ of TNTs for $24 \mathrm{~h}$ caused a larger decline in cell density of NP1 (38.2\%) and SB255 (36.8 \%) in comparison to SB210 (26.5\%) (24).

TNTs are of emerging interest amongst the $\mathrm{TiO}_{2}$ derived nanomaterials since their nanotubular structure bears special advantages in various application fields (25). Therefore, they became promising alternatives of carbon-based nanotubes, especially since they showed no cytotoxicity in a 7 days incubation study on A549 lung epithelial cell 


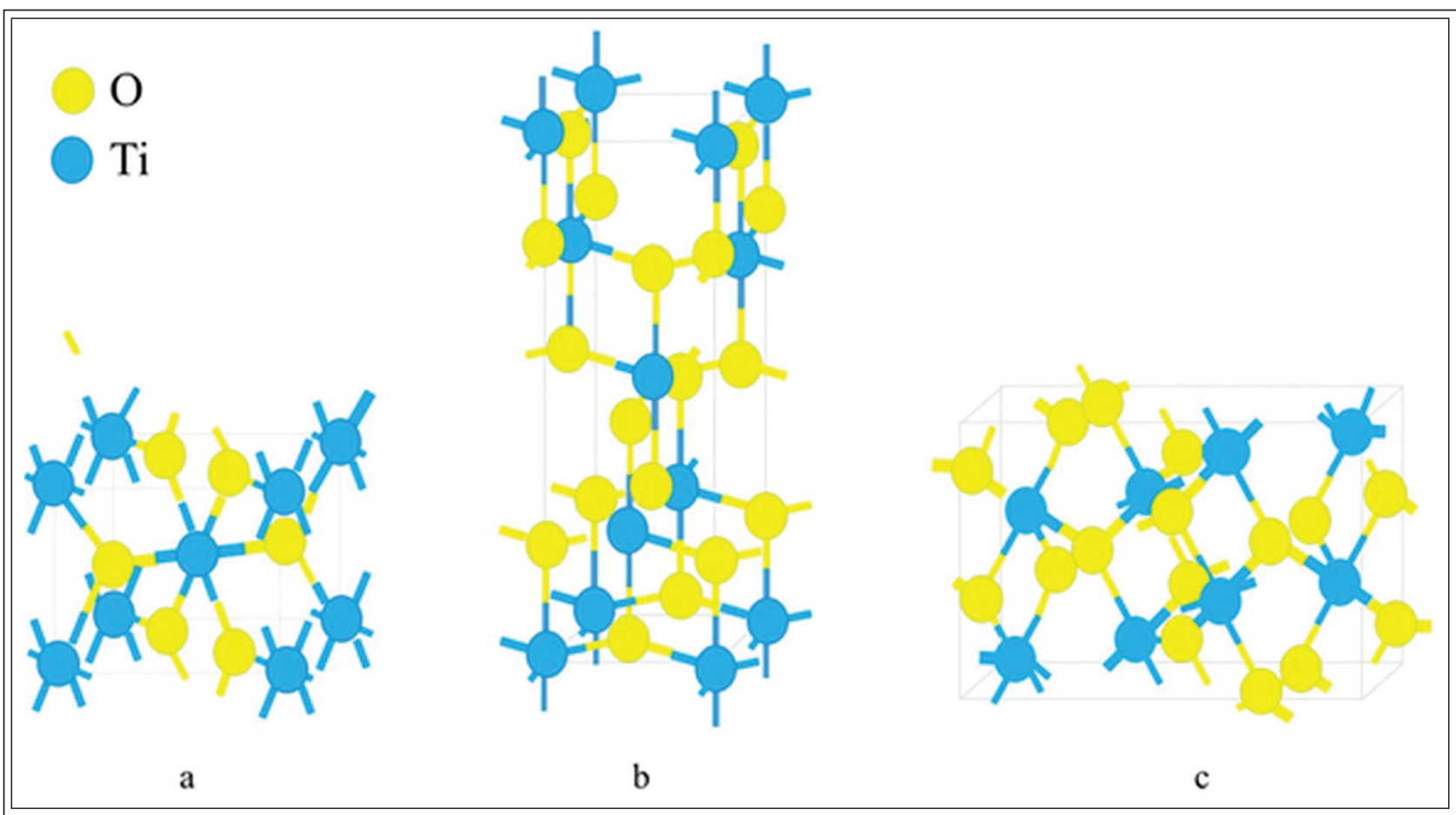

Figure 1 The primitive unit cell of (a) rutile, (b) anatase and (c) brookite $\mathrm{TiO}_{2}$.

lines, in contrast with single-walled- and multiwalled carbon nanotubes (26). Similarly, no cytotoxicity was observed on Caco-2 cells up to $5 \mathrm{mg} /$ $\mathrm{ml}$ concentration, so hydrothermally synthetized TNTs are promising vectors also for intestinal drug delivery, since they do not cause cytotoxicity in short-term treatment and no notable number of TNTs was identified. However, non-tubular highdensity granules were detected on the surface of the endoplasmic reticulum in the treated cells and these granules were identified as $\mathrm{TiO}_{2} \mathrm{NPs}$ that passed into the Caco-2 monolayer (27). Nevertheless, it is notable that the surface charge and characteristics seems to play a key role in titanate cytotoxicity. Sodium titanate $\mathrm{NaxTiOy}+z$ exhibit low risk (26-28) from toxicological aspect, hydrogen titanate $\mathrm{HxTiOy}+\mathrm{z}$ bears considerable risk of cytotoxic effects investigated on H596 human lung tumor cell line $(28,29)$ and on HEp-2 cells $(30)$. Similar signs were observed in some mammalian cell lines investigating manganese or potassium titanate nanotubes and nanofibers possibly by the promoting of reactive oxygen species $(31,32)$.

The functionalization of nanomaterials is important to improve their surface characteristics and achieve the targeted drug delivery. TNTs have negative charge at physiological $\mathrm{pH}$ due to their partially hydroxylated surface, thus they can interact with different molecules (33). TNTs functionalization enhances their stability and increase their capacity as drug carriers (34). A variety of molecules have been used in TNTs functionalization such as using dopamine; tris buffer; bone morphogenetic protein 2 (BMP2) to improve the bone osseointegration, allyltriethoxysilane; propyltriethoxysilane to achieve stable suspensions in tetrahydrofuran (THF), and chitosan to control the drug release; PEG or polyethylene imine (PEI) to improve the dispersion and reactivity of TNTs in water, antimicrobial peptides (HHC-36) to stop the biofilms formation, and 3-aminopropyltriethoxysilane or RGD peptide to enhance the human mesenchymal stem cells (hMSCs) attachment and proliferation (25). The aim of present study was to develop functionalized TNTs with tailored surface characteristics for drug delivery applications and investigate how the functionalization of the highly hydrophilic TNTs will increase their hydrophobicity and may influence their toxicity profile and their absorption from the gastro-intestinal tract.

\section{Materials and Methods:}

The pristine sodium trititanate $\left(\mathrm{Na}_{2} \mathrm{Ti}_{3} \mathrm{O}_{7}\right)$ nanotubes (Na-TNTs) were prepared at the following the general method described by Sipos et al. (35), by dissolving $120 \mathrm{~g}$ of sodium hydroxide $(\mathrm{NaOH})$ in $300 \mathrm{~mL}$ of distilled water on a magnetic stirrer and then adding $75 \mathrm{~g}$ of $\mathrm{TiO}_{2}$ (anatase) for $15 \mathrm{~min}$. Following that, the mixture was moved to the au- 
toclave that was put inside an oven at $185^{\circ} \mathrm{C}$ for 24 $\mathrm{h}$, then cooled at room temperature for $2 \mathrm{~h}$, followed by cooling with cold water. Then, TNTs were washed with distilled water using filter No:4 and under vacuum (35).

Trichloro octyl silane (TCOS) (Sigma-Aldrich, St. Louis, Missouri, United States) were attached to hydrogen trititanate $\left(\mathrm{H}_{2} \mathrm{Ti}_{3} \mathrm{O}_{7}\right)$ nanotubes $(\mathrm{H}-$ TNTs). H-TNTs were prepared by adding $50 \mathrm{~g}$ of the pristine Na-TNTs in $300 \mathrm{~mL}$ of $\mathrm{HCl} 0.01 \mathrm{M}$ in an ultrasonic bath until a homogenous suspension was obtained. Following that, $200 \mathrm{~mL}$ of $\mathrm{HCl} 0.01$ $\mathrm{M}$ was added to the previous suspension on a magnetic stirrer and the mixture was dried in a dry oven for $24 \mathrm{~h}$ to remove the solvent.

TOCS-TNTs were prepared by adding $0.5 \mathrm{~g}$ of $\mathrm{H}$-TNTs to $15 \mathrm{~mL}$ of toluene in ultrasonic bath for $1 \mathrm{~h}$ until a homogenous suspension was obtained. After that, the suspension was heated at $80^{\circ} \mathrm{C}$ in a condenser which was connected to nitrogen gas for $30 \mathrm{~min}$. Then, TCOS was added to the previous system in different volumes, e.g. 1- 2- 10- 50- 100500- $1000 \mu \mathrm{L}$, covering the 0.001:1 - 2:1 molar ratios, respectively and mixed for one day. Finally, the functionalized TNTs were washed by hexane 8 times and dried in a drying oven at $80{ }^{\circ} \mathrm{C}$ (Sanyo Electric Co., Ltd, Osaka, Japan).

$\mathrm{Mg}$-stearate (MgSt) functionalized TNTs were prepared in two step process. In the first step sodium ions of Na-TNTs were replaced with $\mathrm{Mg}$ by adding $100 \mathrm{~g}$ of Na-TNTs to $1 \mathrm{~L}$ of $0.1 \mathrm{M} \mathrm{MgCl}_{2}$ solution on magnetic stirrer for 1 day. Then, the mixture was filtered by using glass filter No\#4 under vacuum to obtain magnesium trititanate $\left(\mathrm{MgTi}_{3} \mathrm{O}_{7}\right)$ nanotubes (Mg-TNTs). This procedure was repeated three times to make sure that no Na-TNTs are existing anymore. Then, Mg-TNTs were washed with distilled water 8 times under vacuum and by using glass filter No\#4. After that, $10 \mathrm{~g}$ of Mg-TNTs were added to $200 \mathrm{ml}$ of distilled water in ultrasonic bath for $30 \mathrm{~min}$. Following that, the mixture was heated to $80^{\circ} \mathrm{C}$ in a magnetic stirrer (Thermo Fisher Scientific, Waltham, MA, USA) and Na stearate (VWR International, Radnor, Pennsylvania, United States) was added in different (e.g. 0.001:10.1:1) molar ratios to this system for 1 night. Finally, St-TNTs were filtered by using filter No\#4 under vacuum and dried in a drying oven.

The morphology of the different preparation of TNTs was investigated by scanning electron microscope (SEM) (Hitachi 4700, Hitachi Ltd., Tokyo, Japan) in which samples were coated with a thin conductive gold layer by a sputter coating unit
(Polaron E5100, VG Microtech, London, UK). The images were taken at an accelerating voltage of $10.0 \mathrm{kV}$, and the used air pressure was $1.3-13 \mathrm{mPa}$ during the analyses. The size of the nanotubes determined using ImageJ 1.51. (National Institute of Health, MD, USA).

The surface free energy of the functionalized TNTs was measured with a DataPhysicsOCA20 (DataPhysics Instruments $\mathrm{GmbH}$, Filderstadt, Germany) optical contact angle tester applying sessile drop method. Polar and apolar test liquids (water and diiodomethane, respectively) were used and dropped onto the surface of $13-\mathrm{mm}$-diameter additive-free comprimates of the samples, which were prepared with a Specac hydraulic press (Specac Ltd., Orpington, UK) at a pressure of 3 tons. Disperse $\left(\gamma_{\mathrm{s}}^{\mathrm{D}}\right)$ and polar $\left(\gamma_{\mathrm{s}}^{\mathrm{p}}\right)$ components of the total surface free energy $\left(\gamma_{\mathrm{s}}\right)$ of the solid were calculated according to $\mathrm{Wu}$ Equations [17].

CHNS elemental analysis was applied for the rapid determination of carbon, hydrogen, nitrogen, and sulphur in organic materials. Samples were analyzed to detect the $\mathrm{H}, \mathrm{C}, \mathrm{N}$, and $\mathrm{S}$ contents in a vario EL cube elemental analyzer (Elementar, Langenselbold, Germany). Sn-foils were filled with 50 to $100 \mathrm{mg}$ samples (no flux added) which were ignited in oxygen-He gas atmosphere furnace at around $1150{ }^{\circ} \mathrm{C} . \mathrm{N}, \mathrm{C}, \mathrm{H}$, and $\mathrm{S}$ were analyzed by releasing the resulted gases in a set of chromatographic columns and analyzing those gases with a thermal conductivity detector. The sample measurement time was 9 mins and was repeated 3 times. All values were calibrated against the reference materials BAM-U110, JP-1, and CRPG BE-N.

Unfunctionalized nanotubes (Na-, $\mathrm{H}-$ and $\mathrm{Mg}$ TNTs), and samples with the possible highest, and moderate hidrophobicity were selected form TCOS- and St-TNT series were selected for toxicity and permeability tests. Permeability and cytotoxicity experiments were tested on Caco-2 human adenocarcinoma cell line. Cells were maintained at $37^{\circ} \mathrm{C}$ in a $5 \% \mathrm{CO}_{2}$ atmosphere by regular passage in Dulbecco's modified Eagle's medium (Sigma-Aldrich), supplemented with $2 \mathrm{mM}$ L-glutamine, $100 \mathrm{mg} / \mathrm{l}$ gentamycin and $10 \%$ heat inactivated foetal bovine serum (Sigma-Aldrich). The passage number of the cells was between 25 and 42. Dulbecco's modified Eagle's medium (SigmaAldrich) was used to keep the cells' regular passage in average of 25 to 42 . Both experiments were performed 7 days after cell passaging when the 


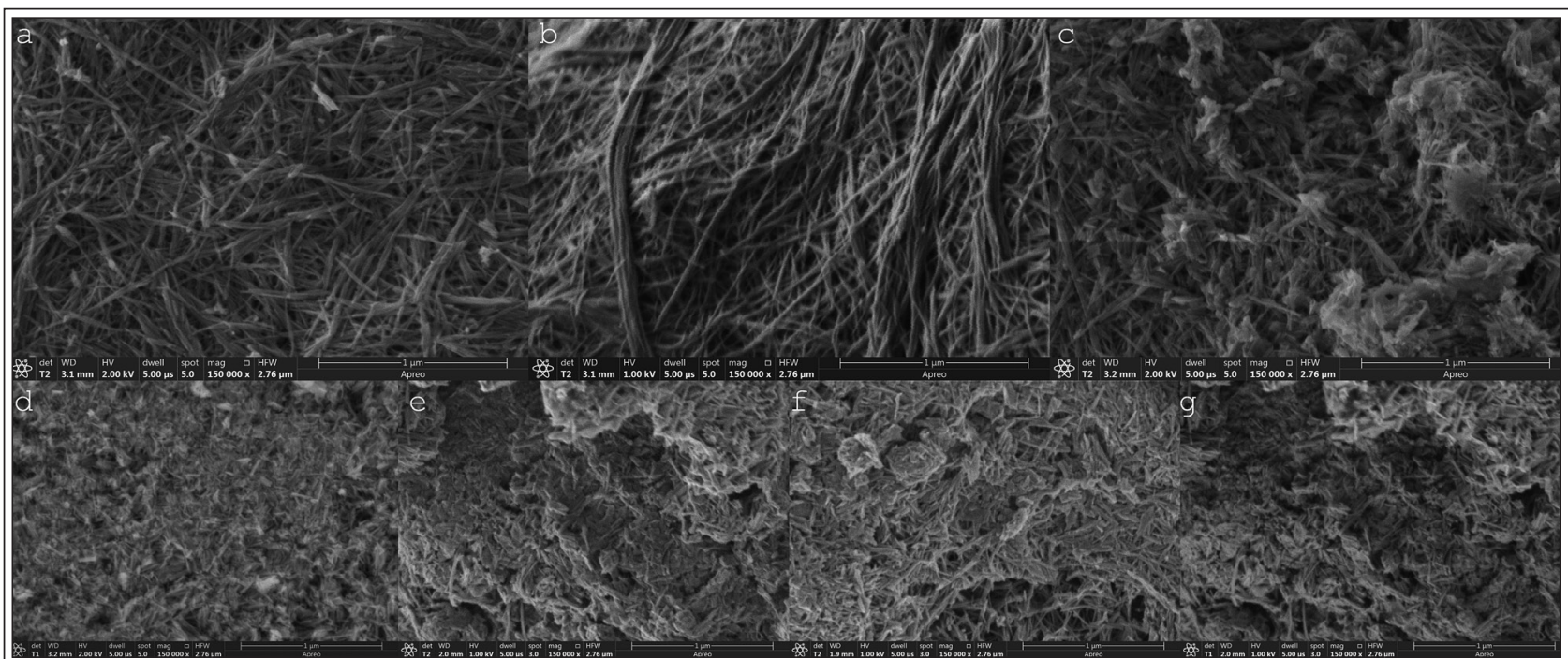

Figure 2 Scanning electron micrographs of Na-TNT (a), H-TNT (b), Mg-TNT (c), TCOS-TNT 10 (d), TCOS-TNT 50 (e), St-TNT $(0,05: 1)(f)$ and St-TNT (0.1:1) ( $g$ ) samples with $150.000 x$ magnification

monolayer was formed. The reagents were purchased from Sigma-Aldrich (Budapest, Hungary) and Caco- 2 cell line was originated from the European Collection of Cell Cultures (UK). The cells had been monitored before and after the treatment via Olympos CKX41 Inverted Microscope by eye estimation. The monolayer did not show any alteration during the procedure.

Cytotoxicity was tested by the 3-(4,5-dimethylthiazol-2-yl)-2,5-diphenyltetrazolium bromide (Sigma catalog no. M2128)(MTT) assay in which Caco-2 cells were implanted in 96-well plates at a final density of 104 cells/well (VWR International, Radnor, Pennsylvania, United States) and exposed to increased concentrations of TNT in Hank's balanced salt solution (HBSS) at $37^{\circ} \mathrm{C}$ for $120 \mathrm{~min}$.

The $5 \mathrm{mg} / \mathrm{ml}$ solution of MTT in PBS was filtered to sterilize and remove the remaining insoluble residue of MTT. The MTT solution $(10 \mu \mathrm{l} / 100$ $\mu l$ medium) was added to all wells which were incubated at $37^{\circ} \mathrm{C}$ for $4 \mathrm{~h}$ followed by the addition of $\mathrm{HCl}$-isopropanol which was mixed rigorously to dissolve the dark blue crystals. Within one hour, the plates were read on a Dynatech MR580 Microelisa reader using a test wavelength of $570 \mathrm{~nm}$, a reference wavelength of $690 \mathrm{~nm}$ and a calibration setting of 1.99 (or 1.00 if the samples were strongly colored). Extreme high concentrations were applied to evaluate MTT test sensitivity in these measurements. To exclude any interferences between the absorbance of living cells performed formazan crystals and the test solutions, a phosphate buffer (PBS) washing method had been deployed after the TNTs sample incubation. Cell via- bility was represented as a percentage of the untreated control.

To test permeability, Caco-2 cells were seeded on ThinCert ${ }^{\mathrm{TM}}$ (Greiner Bio-One, Hungary) inserts at a final density of $8 \times 10^{4}$ cells/insert, and monolayers were incubated apically with $1 \mathrm{mg} / \mathrm{ml}$ TNT for $120 \mathrm{~min}$ after removing cell culture medium. The donor and acceptor phases were then completely removed. The concentration of $\mathrm{Ti}$ in the two phases were measured with an energy dispersive X-ray fluorescent analyzer (Philips MiniPal PW 4025, Philips Analytical, the Netherlands), using standard sample holder, with a 3.6 $\mu \mathrm{m}$ thick polyesterpetp X-ray film. The internal diameter of the sample holders was narrowed to 8 $\mathrm{mm}$ to ensure approx. $1 \mathrm{~cm}$ layer thickness, with $500 \mu \mathrm{L}$ sample volume. $30 \mathrm{~s}$ measurement time was applied with $100 \mu \mathrm{A}$ current and $8 \mathrm{kV}$ acceleration voltage, using Kapton filter. Six parallel measurements were performed with each sample.

\section{Results and discussion}

\section{Physical properties of the functionalized TNTs}

Pristine Na-TNTs (Figure 2a) have considerably elongated structure with 8-12 $\mathrm{nm}$ outer diameter, and highly variable length $(100-1000 \mathrm{~nm})$. H-TNTs (Figure 2b) exert identical physical dimensions but have increased aggregation tendency due the decreasing electrostatic repulsion resulted by the removal of $\mathrm{Na}^{+}$ions. $\mathrm{Mg}$-TNTs (Figure. 2c) have the same 8-12 $\mathrm{nm}$ outer diameter but the mechanical agitation during the ion-exchange procedure re- 


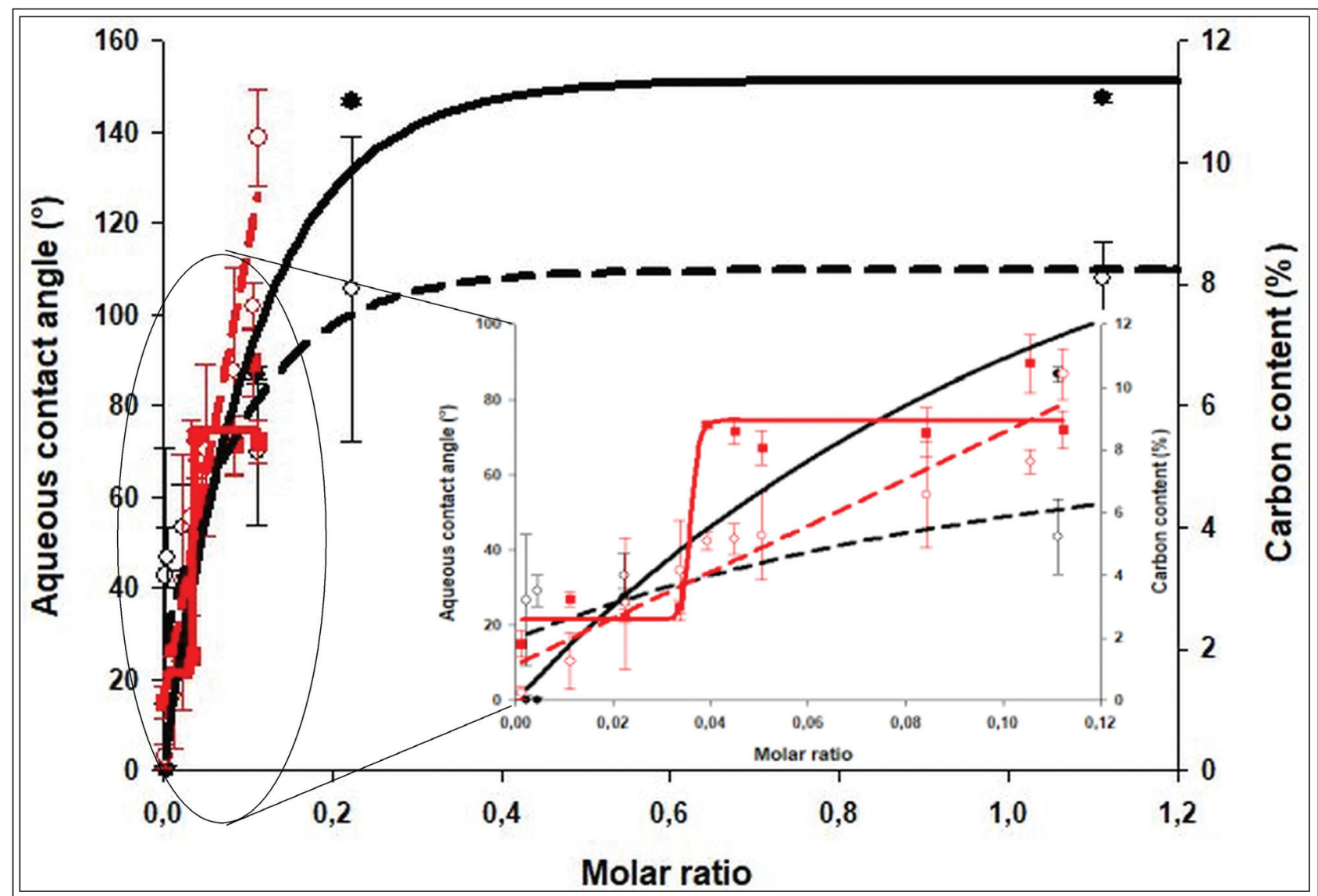

Figure 3 The aqueous contact angles (CA) and carbon percentage (C\%) of TCOS-TNTs and St-TNTs at different reagent concentrations (CA of TCOS-TNT (black line); C\% of TCOS-TNT (black dashed line), CA of St-TNT (red line), C\% of StTNT (red dashed line)

sulted considerable fragmentation, so the length of the nanotubes varies mostly in the $100-300 \mathrm{~nm}$ range. Similar fragmentation of the longer nanotubes was observed in case of the functionalized samples (Figure. 2d-g) along with a slight increment of the outer diameter which depends on the amount and orientation of the functionalizing agent on the TNTs surface. Nevertheless, all samples have strongly elongated tubular structure with an aspect ratio $>10$.

The OCA measurement showed a gradual increment in the aqueous contact angle with the increasing volume of TCOS up to $100 \mu \mathrm{L}$ volume. Those results were supported by the CHNS elemental analysis that displayed a continuous augmentation in carbon percentage with the increasing amount of functionalizing TCOS (Figure.3).

In contrast, the OCA measurement revealed that low concentrations of St could just slightly increase the aqueous contact angle of the Mg-TNTs, but after the exceeding of a certain threshold around 0.035:1 ratio and despite the linear increment of the carbon content, the surface turned from hydrophilic to hydrophobic (Figure. 3). A possible explanation that above this threshold the St molecules are oriented differently on the surface of TNTs, prohibiting the access of water to the sample. After that only a slight increment could be detected until it stabilizes between $80-90^{\circ}$, but it should be noted, that the maximum aqueous contact angle is considerably smaller as in the case of TOCS-TNTs.

\section{Toxicity and permeability of the functionalized TNTs}

In a previous study no detectable cytotoxicity of Na-TNTs was observed up to $5 \mathrm{mg} / \mathrm{ml}$ concentration (27), but in the current study a considerable decrease in cell viability was observed if Mg-TNTs were applied in this concentration (Figure 4). This may indicate that the replacement of $\mathrm{Na}^{+}$to $\mathrm{Mg}^{2+}$ ions on the surface of TNTs also has negative influence on the cell interactions but based on the MTT cytotoxicity test it still be considered as noncytotoxic in the $0,01-2 \mathrm{mg} / \mathrm{ml}$ concentration range. In addition, considerable differences were ob- 


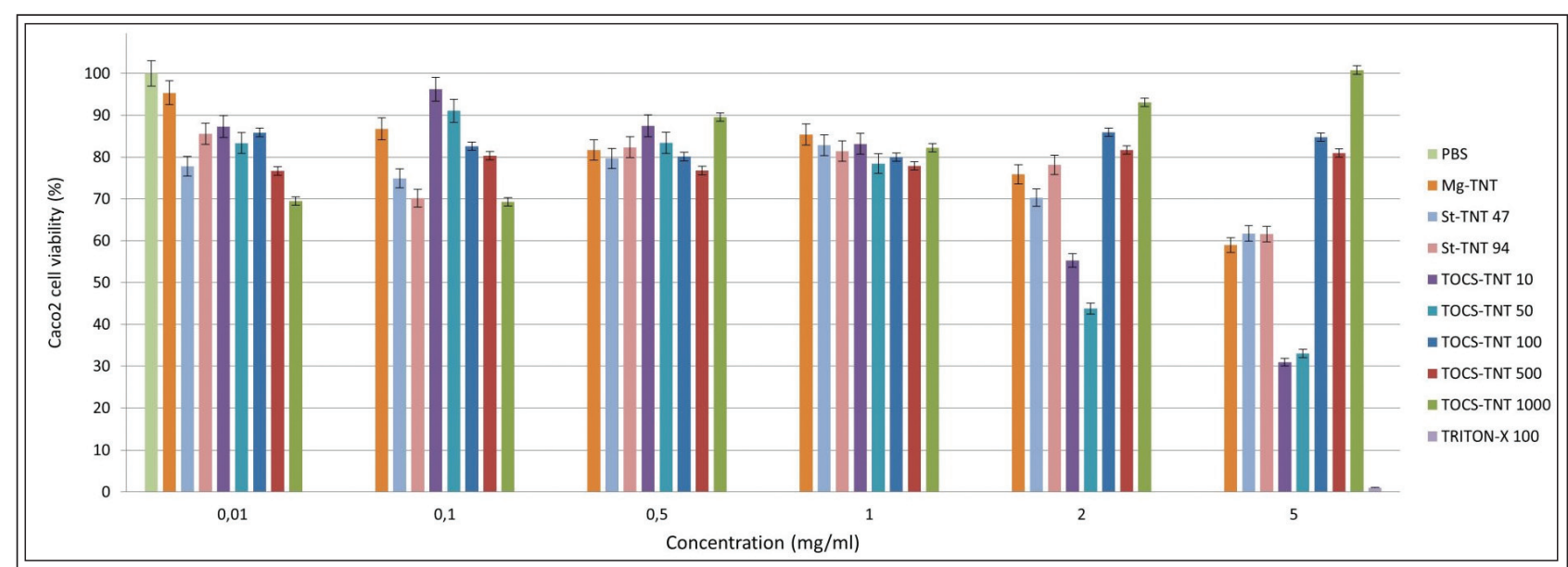

Figure 4 The viability assays of Caco-2 cells after being exposed to functionalized TNTs

served in the toxicity of various functionalized TNTs especially at higher concentrations. In case of St functionalized samples, the cell viability decrease was only observed at $5 \mathrm{mg} / \mathrm{ml}$, which showed no difference from the values observed at Mg-TNTs.

\section{Permeability results:}

During permeability test the highest safe concentration $(1 \mathrm{mg} / \mathrm{ml})$ was applied, to enable the achievement of higher maximum drug-dose during further utilization. The transepithelial electrical resistance (TEER) of the cells before TNTs exposure was $602 \pm 116 \Omega / \mathrm{cm}^{2}$. For Caco- 2 cells this value may vary in a very high range (200-2400 $\Omega$ / $\mathrm{cm}^{2}$ ) (36), the obtained results indicate an intact cell layer. Nevertheless, a considerable relative decrease $(22.1 \pm 16.7 \%, \quad 12.4 \pm 11.1 \%, \quad 37.1 \pm 8.4 \%$ and $23.6 \pm 17.4 \%$ for TCOS-TNT 10, TCOS-TNT 50 , StTNT (0.05:1), and St-TNT (0.1:1) samples, respectively) of the TEER values was observed after TNTs exposure, indicating the perturbation of the integrity of cell-membrane or tight-junctions. However, microscopic investigation showed no change in the cell morphology or layer-integrity, before and after the test, which may indicate a periodic distortion of the membrane integrity by the penetrating nanotubes. Nevertheless, the relative change of various samples showed partial correlation with the results of permeability tests (Table 1), which revealed that the aqueous contact angle (CA) values should be between $60-90^{\circ}$ to achieve appropriate absorption, while the cell integrity was exhibited the smallest distortion for samples between $80-90^{\circ} \mathrm{CA}$. Below $40^{\circ}$ the surface is too hydrophilic to achieve passive transportation through the cell membrane, while in the $40-60^{\circ}$ range the samples may absorbed considerably slower as the ones with $60-90^{\circ} \mathrm{CA}$, and causes higher distortions in cell integrity, possibly due to the higher hydrophilicity.

According to OCA and CHNS measurements for TCOS-TNTs, it is well visible that the increasing amount of the reagent highly increased the surface hydrophobicity and complete surface coverage was achieved by the application of $100 \mu \mathrm{L}$ reagent volume (e.g. 0.2:1 molar ratio). However, the results were different in case of MgSt-TNTs where less St coverage resulted in getting a hydrophobic surface that may bear an advantage of keeping more binding sites for the drugs which may lead to a higher possible drug load in this system.

The toxicity results displayed a considerable decrease in the cell viability in case of TCOS-TNT

Table 1 Results of the permeability tests

\begin{tabular}{l|l|l}
\hline Material & Apical amount (\%) & Basal amount (\%) \\
\hline TCOS-TNT 10 & $40,94 \pm 10,49$ & $8,47 \pm 0,30$ \\
\hline TCOS-TNT 50 & $27,94 \pm 14,83$ & $8,39 \pm 0,24$ \\
\hline TCOS-TNT 100 & n.m & n.m \\
\hline St-TNT 47 & $26,98 \pm 6,66$ & $8,75 \pm 0,78$ \\
\hline St-TNT 94 & $27,16 \pm 11,13$ & $11,49 \pm 0,67$ \\
\hline
\end{tabular}

n.m = not measurable 
10- and 50- samples, possibly due the use of $\mathrm{H}$ TNT as starting material, which would be in accordance of the previously discussed findings (28, 29). However, no similar effect was shown by the 100- 500- and $1000 \mu \mathrm{L}$ samples. A possible explanation, that these samples were too hydrophobic for appropriate dispersion/dissolution in the aqueous media, and therefore were not taken up by the cells. On the other hand, the lower toxicity presented by MgSt-TNTs which was like MgTNTs indicates that the effect may be connected to the presence of $\mathrm{Mg}^{2+}$ ions and not to the St molecules.

In this study, the best permeability rate was observed for samples with $90^{\circ} \mathrm{CA}$, while in case of sample TCOS-TNT 100 where the CA was around $140^{\circ}$ no detectable amount was measured both in apical and basal compartment. A possible explanation that due to the inappropriate wetting and dispersion, the TNTs were sedimented and adhered to the cell layer without visible absorption through the membranes or were completely accumulated in the cells, which would bear a potential risk of toxicity. Nevertheless, in both cases the sample is inappropriate for the planned application.

\section{Conclusions}

In the present study, two various approaches of TNTs functionalization were compared to obtain increased hydrophobicity and enhance their absorption from GIT. TCOS, and St were used for this purpose in different concentrations to optimize the functionalization method and determine the optimal functionalization percentage.

The results revealed a linear relation between the surface hydrophobicity and the concentration of the used TCOS. However, the different molecular size had no significant effect on the hydrophobicity of functionalized TNTs despite the increasing percentage of carbon that was displayed by CHNS elemental analysis. The maximum hydrophobicity was achieved by using $100 \mu \mathrm{L}$ reagent which showed $140^{\circ}$ aqueous CA.

In contrast, St functionalized TNTs exhibited $90^{\circ}$ maximal aqueous $\mathrm{CA}$, which depends nonlinearly on the carbon content. The change in the surface properties after a certain threshold may indicate the changing orientation of St molecules on TNTs surface. This result indicates that turning the surface properties with St is more complicated and can be done in narrower range, but the optimal surface hydrophobicity could still be achieved. Furthermore, the fact that Mg-TNTs exhibit lower degree of cytotoxicity as H-TNTs, and the functionalization is done in aqueous medium instead of organic solvents supports the superiority of the St method for the proposed approach since the preparation was cheaper, faster, easier to be upscaled and less toxic.

\section{Conflict of interest}

The authors declare no conflict of interest.

\section{References:}

1. Hong F, Yu X, Wu N, Zhang YQ. Progress of in vivo studies on the systemic toxicities induced by titanium dioxide nanoparticles. Toxicol. Res. 2017;6:115-133. https://doi.org/10.1039/c6tx00338a

2. Allen R. The cytotoxic and genotoxic potential of titanium dioxide (TiO2) nanoparticles on human $\mathrm{SH}$ SY5Y neuronal cells in vitro. 2016. http://hdl.handle. net/10026.1/14126

3. Samat MH, Ali AM, Taib MF, Hassan OH, Yahya MZ. Hubbard U calculations on optical properties of $3 \mathrm{~d}$ transition metal oxide TiO2. Results Phys. 2016;6:891896. https://doi.org/10.1016/j.rinp.2016.11.006

4. Weir A, Westerhoff P, Fabricius L, Hristovski K, Von Goetz N. Titanium dioxide nanoparticles in food and personal care products. Environ. Sci. Technol. 2012;46:2242-2250. https://doi.org/10.1021/es204168d

5. Vance ME, Kuiken T, Vejerano EP, McGinnis SP, Hochella Jr MF, Rejeski D, Hull MS. Nanotechnology in the real world: Redeveloping the nanomaterial consumer products inventory. Beilstein J. Nanotechnol. 2015;6:1769-1780. https://doi.org/10.3762/bjnano.6.181

6. Chen Z, Wang Y, Zhuo L, Chen S, Zhao L, Luan X, Wang H, Jia G. Effect of titanium dioxide nanoparticles on the cardiovascular system after oral administration. Toxicol. Lett. 2015;239:123-130. https://doi. org/10.1016/j.toxlet.2015.09.013

7. EFSA Panel on Food Additives and Nutrient Sources added to Food (ANS). Re-evaluation of titanium dioxide (E 171) as a food additive. Efsa Journal. 2016;14:e04545. https://doi.org/10.2903/j.efsa.2016.4545

8. IARC Working Group on the Evaluation of Carcinogenic Risks to Humans. Carbon black, titanium dioxide, and talc. IARC monographs on the evaluation of carcinogenic risks to humans. 2010;93:1.

9. Acar MS, Bulut ZB, Ateş A, Nami B, Koçak N, Yıldız B. Titanium dioxide nanoparticles induce cytotoxicity and reduce mitotic index in human amniotic fluidderived cells. Hum Exp Toxicol. 2015;34:74-82. https:// doi.org/10.1177/0960327114530742

10. Jugan ML, Barillet S, Simon-Deckers A, Herlin-Boime N, Sauvaigo S, Douki T, Carriere M. Titanium dioxide nanoparticles exhibit genotoxicity and impair DNA repair activity in A549 cells. Nanotoxicology. 2012;6:501513. https://doi.org/10.3109/17435390.2011.587903

11. Bahadar H, Maqbool F, Niaz K, Abdollahi M. Toxicity of nanoparticles and an overview of current experimental models. Iran. Biomed. J. 2016;20:21. https://doi. org/10.7508/ibj.2016.01.001

12. Wang J, Zhou G, Chen C, Yu H, Wang T, Ma Y, Jia G, Gao Y, Li B, Sun J, Li Y. Acute toxicity and biodistribu- 
tion of different sized titanium dioxide particles in mice after oral administration. Toxicol. Lett. 2007;168:176185. https://doi.org/10.1016/j.toxlet.2006.12.001

13. Mano SS, Kanehira K, Sonezaki S, Taniguchi A. Effect of polyethylene glycol modification of $\mathrm{TiO} 2$ nanoparticles on cytotoxicity and gene expressions in human cell lines. Int. J. Mol. Sci. 2012;13:3703-3717. https://doi. org/10.3390/ijms13033703

14. Tedja R, Soeriyadi AH, Whittaker MR, Lim M, Marquis C, Boyer C, Davis TP, Amal R. Effect of TiO 2 nanoparticle surface functionalization on protein adsorption, cellular uptake and cytotoxicity: the attachment of PEG comb polymers using catalytic chain transfer and thiol-ene chemistry. Polym. Chem. 2012;3:2743-2751. https://doi.org/10.1039/C2PY20450A

15. Warheit DB, Donner EM. Risk assessment strategies for nanoscale and fine-sized titanium dioxide particles: Recognizing hazard and exposure issues. Food Chem. Toxicol. 2015;85:138-147. https://doi.org/10.1016/j. fct.2015.07.001

16. Jones K, Morton J, Smith I, Jurkschat K, Harding AH, Evans G. Human in vivo and in vitro studies on gastrointestinal absorption of titanium dioxide nanoparticles. Toxicol. Lett. 2015;233:95-101. https://doi.org/10.1016/j. toxlet.2014.12.005

17. Catalan-Figueroa J, Palma-Florez S, Alvarez G, Fritz HF, Jara MO, Morales JO. Nanomedicine and nanotoxicology: the pros and cons for neurodegeneration and brain cancer. Nanomedicine. 2016;11:171-187. https:// doi.org/10.2217/nnm.15.189

18. Krawczyńska A, Dziendzikowska K, GromadzkaOstrowska J, Lankoff A, Herman AP, Oczkowski M, Królikowski T, Wilczak J, Wojewódzka M, Kruszewski M. Silver and titanium dioxide nanoparticles alter oxidative/inflammatory response and renin-angiotensin system in brain. Food Chem Toxicol. 2015;85:96-105. https://doi.org/10.1016/j.fct.2015.08.005

19. Geraets L, Oomen AG, Krystek P, Jacobsen NR, Wallin $\mathrm{H}$, Laurentie M, Verharen HW, Brandon EF, de Jong WH. Tissue distribution and elimination after oral and intravenous administration of different titanium dioxide nanoparticles in rats. Part Fibre Toxicol. 2014;11:121. https://doi.org/10.1186/1743-8977-11-30

20. Landsiedel R, Fabian E, Ma-Hock L, Wohlleben W, Wiench K, Oesch F, van Ravenzwaay B. Toxico-/biokinetics of nanomaterials. Arch. Toxicol. 2012;86:10211060. https://doi.org/10.1007/s00204-012-0858-7

21. Kamal N, Zaki AH, El-Shahawy AA, Sayed OM, ElDek SI. Changing the morphology of one-dimensional titanate nanostructures affects its tissue distribution and toxicity. Toxicol. Ind. Health. 2020;36:272-286. https://doi.org/10.1177/0748233720921693

22. Kamal N, Zaki AH, El-Shahawy AA, Sayed OM, ElDek SI. Changing the morphology of one-dimensional titanate nanostructures affects its tissue distribution and toxicity. Toxicol Ind Health. 2020;36:272-286. https://doi.org/10.1016/j.toxlet.2012.08.019

23. van Ravenzwaay B, Landsiedel R, Fabian E, Burkhardt S, Strauss V, Ma-Hock L. Comparing fate and effects of three particles of different surface properties: nano-TiO2, pigmentary $\mathrm{TiO} 2$ and quartz. Toxicol. Lett. 2009;186:152-159. https://doi.org/10.1016/j.toxlet.2008.11.020

24. Kong R, Sun Q, Cheng S, Fu J, Liu W, Letcher RJ, Liu C. Uptake, excretion and toxicity of titanate nanotubes in three stains of free-living ciliates of the genus Tet- rahymena. Aquat. Toxicol. 2021;233:105790. https://doi. org/10.1016/j.aquatox.2021.105790

25. Ranjous Y, Regdon Jr G, Pintye-Hódi K, Sovány T. Standpoint on the priority of TNTs and CNTs as targeted drug delivery systems. Drug Discov. Today. 2019;24:1704-1709. https://doi.org/10.1016/j. drudis.2019.05.019

26. Wadhwa S, Rea C, O'Hare P, Mathur A, Roy SS, Dunlop PS, Byrne JA, Burke G, Meenan B, McLaughlin JA. Comparative in vitro cytotoxicity study of carbon nanotubes and titania nanostructures on human lung epithelial cells. J. Hazard. Mater. 2011;191:56-61. https:// doi.org/10.1016/j.jhazmat.2011.04.035

27. Fenyvesi F, Kónya $Z$, Rázga Z, Vecsernyés M, Kása $P$, Pintye-Hódi K, Bácskay I. Investigation of the cytotoxic effects of titanate nanotubes on Caco-2 cells. AAPS PharmSciTech. 2014;15:858-861. https://doi. org/10.1208/s12249-014-0115-x

28. Maurizi L, Papa AL, Boudon J, Sudhakaran S, Pruvot B, Vandroux D, Chluba J, Lizard G, Millot N. Toxicological risk assessment of emerging nanomaterials: cytotoxicity, cellular uptake, effects on biogenesis and cell organelle activity, acute toxicity and biodistribution of oxide nanoparticles. Unraveling the Safety Profile of Nanoscale Particles and Materials-From Biomedical to Environmental Applications. 2018:17-36. http://dx.doi. org/10.5772/intechopen.71833

29. Magrez A, Horváth L, Smajda R, Salicio V, Pasquier N, Forro L, Schwaller B. Cellular toxicity of TiO2-based nanofilaments. Acs Nano. 2009;3:2274-2280. https://doi. org/10.1021/nn9002067

30. Pan R, Liu Y, Chen W, Dawson G, Wang X, Li Y, Dong B, Zhu Y. The toxicity evaluation of nano-trititanate with bactericidal properties in vitro. Nanotoxicology. 2012;6:327337. https://doi.org/10.3109/17435390.2011.579629

31. Entezari M, Ghanbary F. Toxicity of Manganese Titanate on Rat Vital Organ Mitochondria. Iran J Pharm Res: IJPR. 2019;18:713. https://dx.doi.org/10.22037/ ijpr.2019.1100639

32. Abdelgied M, El-Gazzar AM, Alexander DB, Alexander WT, Numano T, Iigou M, Naiki-Ito A, Takase H, Abdou KA, Hirose A, Taquahashi Y. Pulmonary and pleural toxicity of potassium octatitanate fibers, rutile titanium dioxide nanoparticles, and MWCNT-7 in male Fischer 344 rats. Arch. Toxicol. 2019;93:909-920. https://doi.org/10.1007/s00204-019-02410-Z

33. Papa AL, Maurizi L, Vandroux D, Walker P, Millot N. Synthesis of titanate nanotubes directly coated with USPIO in hydrothermal conditions: a new detectable nanocarrier. J. Phys. Chem. C. 2011;115:19012-19017. https://doi.org/10.1021/jp2056893

34. Papa AL, Boudon J, Bellat V, Loiseau A, Bisht H, Sallem F, Chassagnon R, Bérard V, Millot N. Dispersion of titanate nanotubes for nanomedicine: comparison of PEI and PEG nanohybrids. Dalton Trans. 2015;44:739-746. https://doi.org/10.1039/C4DT02552K

35. Sipos B, Pintye-Hódi K, Kónya Z, Kelemen A, Regdon Jr G, Sovány T. Physicochemical characterisation and investigation of the bonding mechanisms of API-titanate nanotube composites as new drug carrier systems. Int. J. Pharm. 2017;518:119-129. https://doi. org/10.1016/j.ijpharm.2016.12.053

36. Srinivasan B, Kolli AR, Esch MB, Abaci HE, Shuler ML, Hickman JJ. TEER measurement techniques for in vitro barrier model systems. J. Lab. Autom. 2015;20:107-126. https://doi.org/10.1177/2211068214561025 
